STUDI

FRANCESI

\section{Studi Francesi}

Rivista quadrimestrale fondata da Franco Simone

143 (XLVIII | II) | 2004

Varia - fasc. II - maggio-agosto 2004

\title{
Thomas, Le roman de Tristan suivi de La folie Tristan de Berne et La folie Tristan d'Oxford
}

\section{Maria Colombo Timelli}

\section{(2) OpenEdition}

1 Journals

\section{Édition électronique}

URL : https://journals.openedition.org/studifrancesi/38908

DOI : 10.4000/studifrancesi.38908

ISSN : 2421-5856

Éditeur

Rosenberg \& Sellier

\section{Édition imprimée}

Date de publication : 1 décembre 2004

Pagination : 332

ISSN : 0039-2944

\section{Référence électronique}

Maria Colombo Timelli, « Thomas, Le roman de Tristan suivi de La folie Tristan de Berne et La folie Tristan d'Oxford ", Studi Francesi [En ligne], 143 (XLVIII | II) | 2004, mis en ligne le 30 novembre 2015, consulté le 19 mai 2021. URL : http://journals.openedition.org/studifrancesi/38908 ; DOI : https://doi.org/ 10.4000/studifrancesi.38908

Ce document a été généré automatiquement le 19 mai 2021.

\section{(c) $(1) \odot$}

Studi Francesi è distribuita con Licenza Creative Commons Attribuzione - Non commerciale - Non opere derivate 4.0 Internazionale. 


\title{
Thomas, Le roman de Tristan suivi de La folie Tristan de Berne et La folie Tristan d'Oxford
}

\author{
Maria Colombo Timelli
}

\section{RÉFÉRENCE}

THOMAS, Le roman de Tristan suivi de La folie Tristan de Berne et La folie Tristan d'Oxford, Traduction, présentation et notes d'Emmanuèle BAUMGARTNER et Ian Short, avec les textes édités par Félix Lecoy, Paris, Champion, 2003 (“Champion Classiques Moyen Age", 1), pp. 445.

1 Ce Tristan, conservé uniquement par dix fragments (émanant de six manuscrits différents, pour un total de 3294 vers), méritait bien, me semble-t-il, d'être mis à la disposition d'un public non spécialiste dans cette nouvelle collection Honoré Champion. L'Introduction informe synthétiquement sur la diffusion et la transmission de l'œuvre, les motifs qui semblent caractériser cette version du mythe tristanien, l'écriture de Thomas et son langage apparemment sans émotion et centré plutôt sur les nombreuses ressources de la rhétorique médiévale. Le lecteur averti appréciera notamment une lecture qui ne s'éloigne pas du texte et une interprétation qui s'appuie strictement sur les vers conservés du roman. Tout en reproduisant le texte procuré par Félix Lecoy (“CFMA" 113, 1991), les éditeurs rendent compte de l'état des différents fragments et des autres éditions disponibles (cf. le tableau comparatif, pp. 37-38). La traduction en français moderne et en prose est accompagnée de notes où sont surtout discutés les passages et les vers problématiques. Sont réunies à la fin du texte de Thomas toutes les leçons rejetées (pp. 247-258) et les variantes essentielles (pp. 259-261): cette attention philologique est tout aussi appréciable. Un Glossaire (pp. 263-281), qui reprend celui de Lecoy, fournit des correspondances en français moderne 
ou des explications qui n'ont pas toujours été utilisées dans la traduction, plus libre et grâce à cela mieux lisible.

2 La deuxième partie du volume est consacrée aux deux Folies de Berne et d'Oxford. L'Introduction présente les problèmes de fond: l'autonomie' de ces textes, leurs analogies et différences, et surtout le rapport intertextuel qu'elles entretiennent avec le Roman de Tristan. Dans ce cas encore, la version en ancien français est celle de Félix Lecoy, à laquelle sont néanmoins apportées des rectifications et des corrections (cf. la liste p. 297, note 34, et les notes aux vers concernés). L'édition / traduction suit les mêmes principes et la même présentation que celle du texte de Thomas: les leçons rejetées et d'éventuels compléments occupent les pp. 339-341, 417-419; les deux glossaires se trouvent aux pp. 343-348 et 421-429.

3 La bibliographie (pp. 431-442) est utilement organisée en sections: 'Textes' (où les éditions du Tristan de Thomas et des Folies sont données par ordre chronologique de publication), 'Ouvrages de référence', 'Etudes' (on regrette quelques fautes d'impression, dont un amusant 'Varvarò' en clôture de la liste, malgré un 'Varvaro' correct à la p. 440). L'Index des noms propres, qui réunit les occurrences des trois textes édités, complète le volume (pp. 443-445). 